\title{
SAZONALIDADE DE INDICADORES DE QUALIDADE DE ÁGUA EM POÇOS DO MUNICÍPIO DE JABOTICABAL - SP
}

\author{
LOPES, Laudicéia G. ${ }^{1^{*}}$ \\ HOJAIJ, Aparecido ${ }^{1}$ \\ PINTO, Renilto A. ${ }^{1}$ \\ PINTO, Fernanda de R. ${ }^{2}$ \\ AMARAL, Luiz A. do ${ }^{2}$ \\ FERRAUDO, Antônio S. ${ }^{2}$
}

\author{
Recebido em: 2010-02-10
}

Aprovado em: 2010-04-03

ISSUE DOI: $10.3738 / 1982.2278-345$

\begin{abstract}
RESUMO: No Brasil, o entendimento da dinâmica de contaminação das águas subterrâneas sob áreas particulares na área urbana não faz parte do foco das políticas públicas em recursos hídricos. Tendo em vista a importância desse tipo de reservatório e consequentemente dos poços localizados em áreas particulares, este trabalho teve como objetivo efetuar um levantamento da situação das águas de poços localizados na área urbana no município de Jaboticabal-SP e avaliar a sazonalidade da qualidade das águas que apresentavam influência de atividade antrópica indicada pela presença de nitrato acima de $3 \mathrm{mg} \mathrm{N}-\mathrm{NO}_{3} \mathrm{~L}^{-1}$. O levantamento foi realizado a partir de cadastros de poços particulares disponíveis no Serviço Autônomo de Água e Esgoto de Jaboticabal (SAAEJ) e da coleta de amostra de água para análise de nitrato, coliformes totais, Escherichia coli, pH, turbidez e cor aparente. Os resultados indicaram que, embora a qualidade das águas amostradas em Jaboticabal-SP tenha se mostrado superior quando comparada com resultados publicados para outras áreas urbanas brasileiras, a contaminação é bastante variável com o tempo. A principal variação foi encontrada para Escherichia coli com grande depreciação da qualidade em período chuvoso. Concluiu-se que, no que se refere ao consumo humano e em período chuvoso, estas águas podem oferecer risco à saúde e demandam maior atenção dos sistemas de gerenciamento dos recursos hídricos com vistas ao controle da poluição.
\end{abstract}

Palavras-chave: Nitrato. Água subterrânea. Água potável.

\section{SEASONALITY OF THE INDICATORS OF THE QUALITY OF WATER IN WELLS IN THE MUNICIPAL OF JABOTICABAL, SÃO PAULO}

SUMMARY: In Brazil the understanding of the dynamics of subterranean water contamination in private urban areas is not a concern for public policy in hydro resources. Due to the importance having been seen of this type of reservoir and consequently of the wells located in private areas, the objective of this work was to study the situation of the well water located in the urban area of the municipal of Jaboticabal, São Paulo, and to evaluate the seasonality of the water quality that presented an influence of human activity indicated by the presence of nitrate above $3 \mathrm{mg} \mathrm{N}-\mathrm{NO}_{3} \mathrm{~L}^{-1}$. The study commenced with the registers of private wells available at the Autonomous Service of Water and Sewage of Jaboticabal (SAAEJ) and the collection of water samples to analyze the nitrate, total coliform bacteria, Escherichia coli, $\mathrm{pH}$, turbidity and apparent colour. The results indicate that, although the quality of the water samples in Jaboticabal-SP have demonstrated to be superior when compared with published results for other Brazilian urban areas, contamination is quite variable with the weather. The principal variation was in Escherichia coli, with a great deterioration in quality in the rain season. To conclude, when referring to human consumption and the rain season, these waters could offer a risk to health and thus demand more attention to the generating systems of the hydro resources with views to controlling pollution.

\footnotetext{
${ }^{1}$ Serviço Autônomo de Água e Esgoto de Jaboticabal, e-mail: laudiceia_lopes@globo.com; eta@saaej.com.br; r_aryano@ superig.com.br

${ }^{2}$ Faculdade de Ciências Agrárias e Veterinárias da UNESP, Campus de Jaboticabal, e-mail: f_rezendevet@yahoo.com.br; lamaral@fcav.unesp.br; fsajago@gmail.com

* A quem a correspondência deve ser enviada.
} 
Keywords: Nitrate. Subterranean water. Potable water .

\section{INTRODUÇÃO}

$\mathrm{O}$ entendimento da variação temporal da qualidade da água é importante para a segurança do consumo, porque as fontes de contaminação podem atuar de forma contínua ou intermitente e em padrões específicos para cada região.

De acordo com a Cetesb (2003), as diferentes formas de aporte tornam inexequíveis a análise de todos os poluentes que podem estar presentes nas águas. Diante disso, alguns parâmetros devem ser selecionados para que possam atuar como descritores da situação da qualidade das mesmas.

Historicamente, coliformes termotolerantes, Escherichia coli, coliformes totais e estreptococos fecais têm sido usados como indicadores de qualidade de água. Em ambiente urbano, os coliformes termotolerantes têm origem exclusiva no esgoto e são considerados como marcadores de recarga de aquíferos pelo mesmo, pois estão presentes em alto número nas fezes, mas ausentes em outras fontes (BARRET et al., 1999). Paralelamente, estudos sobre a distribuição e a persistência dos coliformes totais no ambiente esclareceram que muitas bactérias podem ser isoladas de fontes ambientais livres de contaminação fecal.

Além desses indicadores microbiológicos, o nitrato também se destaca pela importância para a saúde pública. Esse se encontra naturalmente em concentrações moderadas em muitos ambientes, mas é frequentemente enriquecido em níveis contaminantes e tem sido associado principalmente ao uso de fertilizantes. No entanto, existem outras fontes relacionadas ao desenvolvimento urbano que podem aumentar a concentração de nitrato em águas subterrâneas (WAKIDA; LERNER, 2005). Entre essas, estão os vazamentos da rede de esgoto, de fossas sépticas, de esgotos industriais, de áreas contaminadas com depósito de lixo e de resíduos industriais, interações entre rios e aquíferos, fertilizantes usados em jardins, hortas e praças, construções civis, deposição atmosférica, resíduos animais, entre outras.

No estudo da composição do aquífero próximo ao Rio Pisuerga, Espanha, o nitrato esteve associado ao $\mathrm{pH}$ e a elementos-traços (cádmio e cobre), espécies cuja presença em altos níveis são atribuídas a ações antrópicas, tais como a dispersão de fertilizantes e de resíduos industriais (HELENA et al., 2000).

$\mathrm{Na}$ cidade de Nottingham, Inglaterra, foi avaliado potenciais marcadores de recarga urbana de origem inorgânica ( por exemplo, boro e fósforo, presentes nos detergentes ), 
orgânica (clorofórmio, subproduto de cloração da água), particulada (E. coli, estreptococos fecais e enterovírus) e isotópica $\left({ }^{34} \mathrm{~S}_{(\mathrm{SO} 4)},{ }^{18} \mathrm{O}_{(\mathrm{SO} 4)}\right.$ e $\left.{ }^{15} \mathrm{~N}_{(\mathrm{NO} 3)}\right)$ (BARRET et al., 1999). Os autores observaram que a combinação de indicadores fecais microbiológicos e isótopos de nitrogênios foram os marcadores com melhor indicação de presença de esgoto em recarga de águas subterrâneas. Sendo assim, o nitrato consiste em um indicador que, juntamente com outros parâmetros não específicos (turbidez, cor aparente, $\mathrm{pH}$ ) e microbiológicos (coliformes totais e termotolerantes), pode oferecer informações sobre a condição da água e a influência do entorno do poço.

Além de indicador, o nitrato também é considerado contaminante, pois a exposição a altos níveis de nitrato foi associada à ocorrência de nascimentos com problemas no sistema nervoso central (ARBUCKLE et al., 1988) e ao aumento de casos de câncer do útero e melanoma maligno (FLATEN; BOLVIKEN, 1991).

Outros efeitos da exposição a nitratos pelo abastecimento com águas de sistemas públicos e alternativos também foram pesquisados. Weyer et al. (2001) avaliaram a relação entre a qualidade de água (para nitratos) e a incidência de câncer em 21.977 mulheres entre 55 e 69 anos, que haviam utilizado a mesma fonte de água por, no mínimo, dez anos. Os autores observaram correlação positiva com câncer de bexiga e de ovários. Dentre o total de mulheres estudadas, 25\% eram abastecidas com água de fontes que não pertenciam à rede pública, mostrando que a qualidade desse tipo de abastecimento também pode influir no surgimento de patologias importantes.

A manutenção da qualidade de água de poços particulares é importante para preservar a saúde pública e consiste num desafio complexo. Nos Estados Unidos, 1.255 poços de água potável domésticos foram amostrados entre 1992 e 1999 (SQUILLACE et al., 2002). Desses, $28 \%$ apresentavam nitrato antropogênico, ou seja, em concentrações acima de $3,0 \mathrm{mg} \mathrm{N}-\mathrm{NO}_{3} \mathrm{~L}^{-1}$.

Em estudo com poços domésticos na Carolina do Sul, Estados Unidos, dos 70 poços amostrados, o nitrato esteve presente acima de 1,0 mg L $\mathrm{L}^{-1}$ em 20 deles (AELION; CONTE, 2004). Dentre os fatores estudados (densidade populacional, área cultivada, porcentagem de declividade do relevo e textura do solo), a área cultivada com pasto foi o que mais aumentou a probabilidade de contaminação dos poços domésticos com nitrato.

Entre as regiões do Brasil, cujas águas subterrâneas urbanas foram avaliadas, está o município de Belo Horizonte - MG (BEATO et al., 2003), onde foram cadastrados 147 poços e, em parte desses, cujas águas foram analisadas, 9,2\% dos resultados estavam fora dos padrões de potabilidade descritos na legislação (BRASIL, 2004). A falta de infraestrutura de 
saneamento (disposição inadequada de resíduos sólidos e esgoto) foi apontada pelos autores como a principal fonte de contaminação. A disposição inadequada de esgoto também foi a principal causa de depreciação da qualidade de águas subterrâneas no Parque Ecológico do Tietê, São Paulo - SP (VARNIER; HIRATA, 2002). Em Fátima do Sul - MS, houve correlação entre a proximidade das fossas sépticas e o poço contendo água contaminada por coliformes termotolerantes (JÚNIOR et al., 2008).

O controle e o entendimento da evolução temporal da qualidade das águas subterrâneas para períodos superiores a um ano é importante, porém incomum devido à ausência de dados históricos. Em Fife, na Escócia, na década de 1970, a concentração de nitratos estava em 4,5 mg N-NO $\mathrm{L}^{-1}$, e na década de 1990, estava em 11,0 mg N-NO $\mathrm{L}^{-1}$ (VINTEN; DUNN, 2001). Como exemplo, pode-se citar a cidade de Guiyang, no Sudeste da China, onde Liu et al. (2006) observaram que as principais fontes de nitrato para as águas subterrâneas de água são a agricultura no verão e a dispersão de esgoto no inverno.

O nitrato também pode ser removido do aquífero por processos que promovem a atenuação. A desnitrificação, que consiste na redução de $\mathrm{NO}_{3}$ a $\mathrm{N}_{2}$ (gás), é considerada como a mais importante e é influenciada pela concentração de nitrato, de oxigênio, disponibilidade de nutrientes, $\mathrm{pH}$, temperatura, salinidade, presença de toxinas, porosidade do aquífero e adaptação microbiana (RIVETT et al., 2008). A nitrificação prevalece quando o carbono orgânico é limitante e pode ocorrer em ambientes facultativos.

Os poços particulares representam significativo risco à saúde devido à exposição aguda ou crônica a poluentes que podem estar presentes nessas águas. Além disso, existem dúvidas acerca da extensão desse tipo de abastecimento e da influência da variação temporal e do uso do solo na contaminação das águas subterrâneas de áreas urbanas (REID et al., 2003).

No Brasil, ao longo dos anos, tem-se observado aumento no consumo de água de fontes, como minas e poços particulares. Embora esse tipo de abastecimento tenha sido normalizado pela Portaria MS 518 (BRASIL, 2004), poucos dados foram gerados sobre as condições sanitárias, a qualidade das águas e os tipos (finalidade) de usos desses sistemas.

Sendo assim, os objetivos deste trabalho compreenderam a avaliação da água de 40 poços e da sazonalidade da qualidade da água de oito poços previamente selecionados com base na presença de nitrato acima de $3 \mathrm{mg} \mathrm{N}-\mathrm{NO}_{3} \mathrm{~L}^{-1}$ durante o período de um ano na cidade de Jaboticabal - SP.

\section{MATERIAL E MÉTODOS}

\section{Caracterização da área em estudo}

O município de Jaboticabal está localizado nas coordenadas $21^{\circ} 15^{\prime}$ latitude sul e $48^{\circ} 18^{\prime}$ 
longitude WG, e pertence à região administrativa de Ribeirão Preto, localizada na porção centro-norte do Estado de São Paulo. Constitui-se, também, em parte da bacia hidrográfica do Córrego Rico, afluente do Rio Mogi Guaçu.

Para o desenvolvimento deste trabalho, foram considerados como sistemas alternativos de abastecimento, os poços não pertencentes ao sistema público de abastecimento, situados no perímetro urbano. As coletas foram conduzidas no período entre dezembro/2008 (mês 1) e novembro/2009 (mês 12).

A elaboração do cadastro das fontes foi efetuada por meio da aplicação de questionário nos endereços de proprietários de poços que constavam nos arquivos do Serviço Autônomo de Água e Esgoto de Jaboticabal (SAAEJ), referentes aos imóveis que apresentavam $0 \mathrm{~m}^{3}$ de consumo de água de abastecimento, indicativo de propriedades com poços particulares.

\section{AVALIAÇÃO DAS FONTES}

A seleção das fontes ocorreu por meio da coleta de amostras de 40 poços cadastrados, de acordo com procedimentos-padrão (AMERICAN PUBLIC HEALTH ASSOCIATION, 1992). Essas foram enviadas para o Laboratório do SAAEJ, onde foram analisados nitrato, coliformes totais, Escherichia coli, $\mathrm{pH}$, turbidez e cor aparente, de acordo com os métodos descritos a seguir.

Nitrato: determinado de acordo com o método de redução por cádmio, adaptado pela Hach Company (HACH, 1996), em espectrofotômetro da marca Hach, modelo DR 2000.

Coliformes totais e Escherichia coli (AMERICAN PUBLIC HEALTH ASSOCIATION, 1992): para a utilização de método do substrato cromogênico fluorescente, foram transferidos $100 \mathrm{~mL}$ de amostra para frasco de vidro estéril de $250 \mathrm{~mL}$ e adicionado o meio Colilert (Idexx). Após agitação e completa dissolução, a mistura foi transferida para cartela Quanti-Tray/2000, selada em seladora Quanti-Tray. Após incubação das cartelas a $35^{\circ} \mathrm{C}$ por 24 horas, foram contadas as concavidades com coloração amarela e, consultando a tabela de Número Mais Provável (NMP), os resultados foram expressos em NMP $100 \mathrm{~mL}^{-1}$. A exposição da mesma cartela à luz ultravioleta de $365 \mathrm{~nm}$ possibilitou a contagem de concavidades com fluorescência produzida por Escherichia coli quando utiliza $\beta$-gluconidase para metabolizar MUG (4 metil umberliferil $\beta$-d- glucoronídeo), que foram expressas depois de consultada a tabela de Número Mais Provável como NMP $100 \mathrm{~mL}^{-1}$.

pH: determinado em pHmetro da marca Orion, modelo 310;

Turbidez: determinada de acordo com o método turbidimétrico (HACH, 2008), em turbidímetro da marca Hach, modelo 2100P. 
Cor aparente: determinada de acordo com o método colorimétrico do Standard Methods for the Examination of Water and Wastewater, adaptado pela Hach Company (HACH, 1996), em espectrofotômetro da marca Hach, modelo DR 2000.

A partir dessa primeira etapa, conduzida a análise de amostras de 40 poços em um mês, foi iniciada a segunda etapa, que compreendeu a avaliação temporal da qualidade da água por meio do monitoramento mensal, com os indicadores utilizados anteriormente, de oito fontes dos Grupos 2 e 3, de acordo com o agrupamento e o critério descritos a seguir:

- Grupo 1: fontes com nitrato de origem natural com concentração de nitrato inferior a 3,0 $\mathrm{mg} \mathrm{N}-\mathrm{NO}_{3} \mathrm{~L}^{-1}$;

- Grupo 2: fontes com nitrato antropogênico (SQUILLACE et al., 2002), concentração de nitrato entre $3,0 \mathrm{mg} \mathrm{N}-\mathrm{NO}_{3} \mathrm{~L}^{-1}$ e $10 \mathrm{mg} \mathrm{N}-\mathrm{NO}_{3} \mathrm{~L}^{-1}$, e

- Grupo 3: fontes com nitrato acima do limite estabelecido na Portaria MS 518 (BRASIL, 2004), com concentração de nitrato acima de $10 \mathrm{mg} \mathrm{N}-\mathrm{NO}_{3} \mathrm{~L}^{-1}$.

\section{RESULTADOS E DISCUSSÃO}

As médias dos resultados obtidos nas análises físico-químicas e microbiológicas de amostras de 40 poços localizados na área urbana estão apresentadas na Tabela 1.

Tabela 1. Média dos resultados de indicadores físico-químicos e microbiológicos de qualidade de água para poços localizados na área urbana do município de Jaboticabal - SP.

\begin{tabular}{lcc}
\hline Parâmetro & Unidade & Resultados \\
\hline Nitrato & $\mathrm{Mg} \mathrm{N}-\mathrm{NO}_{3} \mathrm{~L}^{-1}$ & 2,0 \\
Coliformes totais & $\mathrm{NMP} 100 \mathrm{~mL}^{-1 *}$ & 517 \\
Escherichia coli & $\mathrm{NMP} 100 \mathrm{~mL}^{-1}$ & 3 \\
pH & & 6,33 \\
Turbidez & $\mathrm{NTU}^{*}$ & 2,16 \\
Cor aparente & $\mathrm{uH}^{*}$ & 14 \\
\hline * NTU - unidade nefelométrica de turbidez; uH - unidade Hazen; NMP $100 \mathrm{~mL}^{-1}$ - número mais provável por \\
$100 \mathrm{~mL}$.
\end{tabular}

A média para nitrato foi de $2,0 \mathrm{mg} \mathrm{N}-\mathrm{NO}_{3} \mathrm{~L}^{-1}$ e esteve abaixo dos resultados obtidos para Aberdeenshire, Inglaterra, de $30 \mathrm{mg} \mathrm{NO}_{3} \mathrm{~L}^{-1}\left(7 \mathrm{mg} \mathrm{N}-\mathrm{NO}_{3} \mathrm{~L}^{-1}\right.$ ) (REID et al, 2003) e para Sparta, na Grécia, onde a concentração média foi de $62,16 \mathrm{mg}-\mathrm{NO}_{3} \mathrm{~L}^{-1}$ (correspondendo a 14,00 mg N-NO $\mathrm{L}^{-1}$ ) (ANTONAKOS; LAMBRAKIS, 2000).

Para coliformes totais e E. coli, foram observadas as médias de $517 \mathrm{NMP} 100 \mathrm{~mL}^{-1} \mathrm{e}$ 3 NMP $100 \mathrm{~mL}^{-1}$, respectivamente. Esses resultados também foram encontrados como sendo melhores que os publicados para aquíferos rasos não confinados sob áreas residenciais de Nottingham, Inglaterra, onde coliformes totais variaram entre 1 e $910 \mathrm{NMP} 100 \mathrm{~mL}^{-1}$, e $E$. 
coli entre 1 e 160 NMP $100 \mathrm{~mL}^{-1}$, indicando a presença de esgoto na recarga (BARRET et al, 1999).

Os resultados também se apresentaram melhores que os observados em Kampala, Uganda, onde foram avaliados poços para E. coli e foi observada contagem entre menor que 1 até 23.000 UFC $100 \mathrm{~mL}^{-1}$. Neste caso, houve relação com a incidência de chuva ocorrida até 48 horas antes da coleta, demonstrando a infiltração direta de material fecal (HOWARDA et al, 2003).

As médias para $\mathrm{pH}$, turbidez e cor aparente foram 6,33; 2,16 NTU e $14 \mathrm{uH}$, respectivamente. Os resultados obtidos em Jaboticabal indicaram superioridade da qualidade da água, comparados com os resultados descritos na literatura para áreas urbanas de regiões metropolitanas brasileiras, como Belo Horizonte e Natal. Na Tabela 2, com exceção para pH, os parâmetros para as regiões metropolitanas superam os de Jaboticabal, o que sugere a influência da infraestrutura urbana sob a qualidade de águas subterrâneas.

Após o levantamento inicial feito com amostras de 40 poços, foram selecionados oito poços que apresentavam a concentração de nitrato acima de $3 \mathrm{mg} \mathrm{N}-\mathrm{NO}_{3} \mathrm{~L}^{-1}$, que, de acordo com Squillace et al. (2002), indica influência antropogênica para acompanhamento ao longo do período de um ano. A variação temporal da precipitação pluviométrica mensal para o período em estudo (Figura 1) indica que, entre dezembro/2008 (primeiro mês do monitoramento) e maio/2009 (sexto mês do monitoramento), houve redução da mesma. Essa, em seguida, nos meses de junho e junho, manteve-se constante e, a partir de agosto/2009, ocorreu aumento referente ao início do período de chuvas.

Tabela 2. Resultados de parâmetros de qualidade de água obtidos para Jaboticabal - SP, e de estudos descritos na literatura.

(Continua)

\begin{tabular}{ccccc}
\hline \multirow{2}{*}{ Parâmetro } & \multirow{2}{*}{ Jaboticabal } & \multicolumn{3}{c}{ Outros estudos } \\
\cline { 2 - 5 } & & Resultados & Local & Referência \\
\hline \multirow{2}{*}{$p H$} & $4,79-8,83$ & $5,35-7,15$ & Belo Horizonte & Beato et al (2003) \\
& & $5,5-7,6$ & Natal & Lucena et al (2004) \\
& & $3,5-7,2$ & Belém & Cabral (2007) \\
\hline \multirow{2}{*}{ Turbidez $(\mathrm{NTU})$} & $0,03-372$ & $0,20-404$ & Belo Horizonte & Beato et al (2003) \\
Cor aparente $(u H)$ & & $0->200$ & Natal & Lucena et al (2004) \\
Nitrato & $0-10,3$ & $0->100$ & Natal & Lucena et al (2004) \\
$\left(\right.$ Mg N-NO $\left._{3} \mathrm{~L}^{-1}\right)$ & & $0-6,19$ & Belo Horizonte & Beato et al (2003) \\
& & $0,58-12,3$ & Belém & Cucena et al (2004
\end{tabular}


Tabela 2. Resultados de parâmetros de qualidade de água obtidos para Jaboticabal - SP, e de estudos descritos na literatura.

(Conclusão)

\begin{tabular}{ccccc}
\hline $\begin{array}{c}\text { Coliformes totais } \\
\left(\text { NMP } 100 \mathrm{~mL}^{-1}\right)\end{array}$ & $<1->2.420$ & $<2-2.400$ & Belo Horizonte & Beato et al. (2003) \\
& 8.960 & Jaboticabal & Amaral et al. (1994) \\
\hline Coliformes & $<1-57$ & $<2-2.400$ & Belo Horizonte & Beato et al. (2003) \\
termotolerantes & 908 & Jaboticabal & Amaral et al. (1994) \\
$\left(\mathrm{NMP} 100 \mathrm{~mL}^{-1}\right)$ & & & & \\
\hline
\end{tabular}

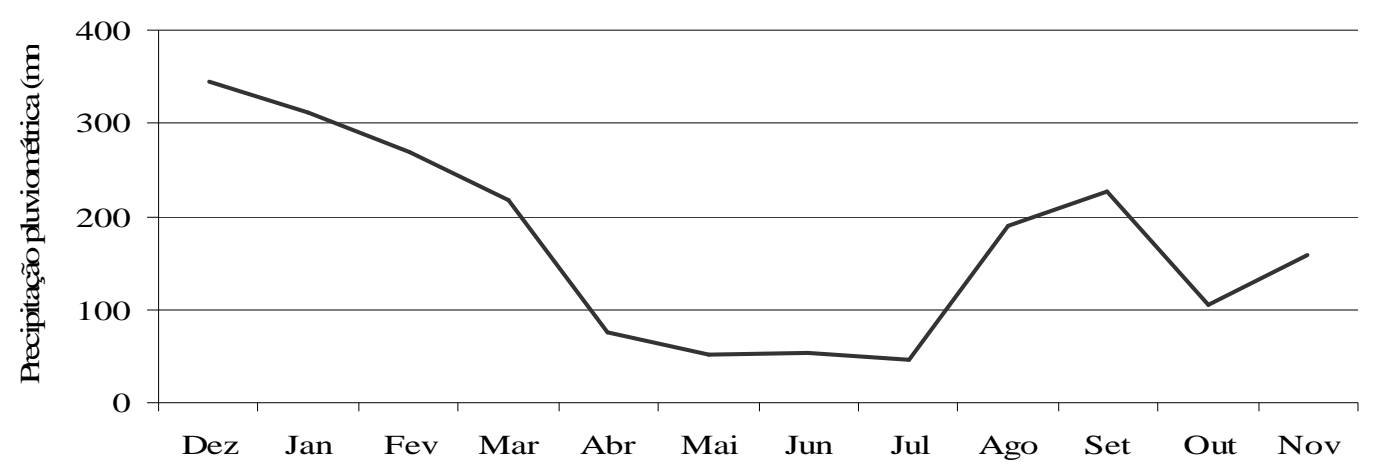

Figura 1. Precipitação pluviométrica mensal para o período de dezembro-2008 a novembro2009, Jaboticabal - SP. Fonte: Pluviômetro da ETA do SAAEJ.

Para nitrato (Figura 2), observou-se diluição nos primeiros cinco meses do monitoramento, os quais foram coincidentes com o período chuvoso. Em seguida, a redução das chuvas provocou concentração do nitrato presente, o que ocorreu até o mês 7 (junho/2009). No mês 8 (julho/2009), com o início das chuvas, houve redução, que pode ser atribuída à diluição. Em seguida, a continuação das chuvas foi acompanhada de aumento da concentração de nitrato.

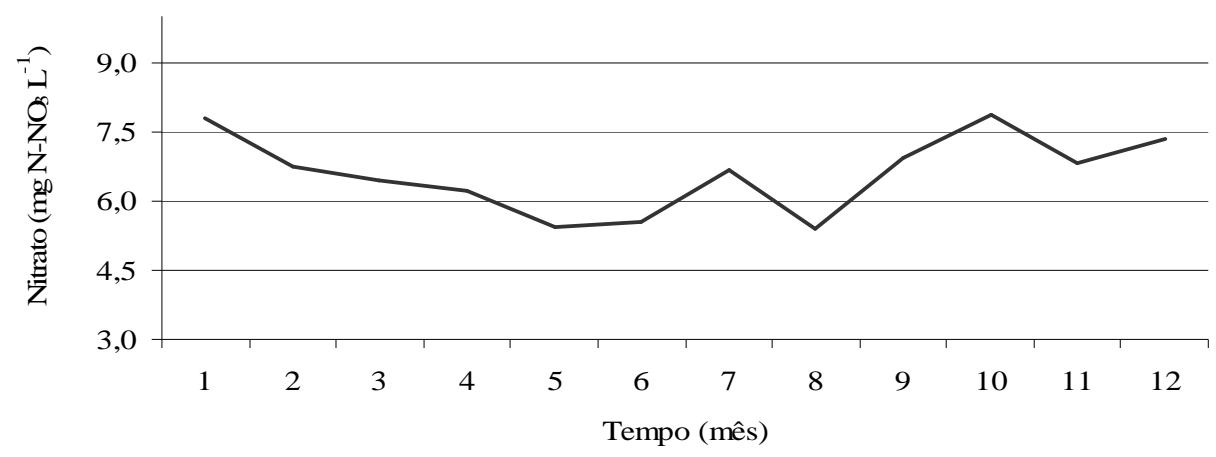

Figura 2. Médias dos resultados mensais de nitrato para oito poços monitorados no município de Jaboticabal - SP.

De acordo Clay et al (1996), quando o nível da água do aquífero permanece constante ao longo do ano, a concentração de nitrato também se mantém constante, considerando-se aquíferos rasos em Brookings, EUA. 
No estudo conduzido no Alabama, EUA, durante a primavera e o verão, maior quantidade de chuva correspondeu à maior concentração de nitrato (LIU et al., 2005). No entanto, para os meses de setembro e outubro, a correlação foi inversa: setembro chuvoso e outubro seco corresponderam à menor e à maior concentrações de nitrato em água, respectivamente, fato que foi explicado com base nas atividades agrícolas. Os fertilizantes eram aplicados em maior quantidade durante a primavera e o verão, coincidindo com o aumento das chuvas e da concentração de nitrato. Entretanto, as atividades agrícolas eram reduzidas na estação do outono e o aumento adicional das chuvas resultava no efeito de aumento do nível do aquífero ou diluição da água subterrânea com a água de chuva.

No estudo da composição de aquífero próximo ao Rio Pisuerga, Espanha, houve aumento da concentração de nitrato em período de chuva. Esse fato foi atribuído à liberação do solo devido ao aumento do nível do lençol no período de recarga (HELENA et al., 2000).

No aquífero Barreiras, em Belém - PA, foram avaliados nitrato $\left(\mathrm{NO}_{3}{ }^{-}\right)$, amônio $\left(\mathrm{NH}_{4}{ }^{+}\right)$, pH e condutividade nos meses de junho, setembro, dezembro, fevereiro e março (nos anos de 2000 a 2002) e era esperado que houvesse diluição no período chuvoso (CABRAL, 2007). No entanto, essa não ocorreu, sendo observado que a carga urbana proveniente dos efluentes domésticos exerceu maior importância no comportamento dessas águas em detrimento das variações sazonais locais. Paralelamente, os autores avaliaram que o processo de urbanização onde ocorre a pavimentação e a impermeabilização de grandes áreas (ruas, residências, etc.) reduz a recarga natural dos aquíferos, isto é, aquela proveniente da precipitação pluviométrica. A diminuição dessa recarga natural afeta o fluxo subterrâneo e a diluição de contaminantes, enquanto a recarga oriunda dos efluentes domésticos tende a ser crescente e constante.

Os resultados obtidos para coliformes totais (Figura 3) mostraram elevadas populações em períodos chuvosos, no início e no final do monitoramento (exceto para o mês 9 agosto/2009 - quando as chuvas já haviam iniciado e a população do microrganismo se manteve baixa), demonstrando o carreamento por infiltração com as chuvas e sugerindo vulnerabilidade construtiva. Houve, também, picos no período da seca em junho e julho (mês 5 e 6 do monitoramento), indicando outros aportes diferentes da infiltração por ocorrência de chuvas. 


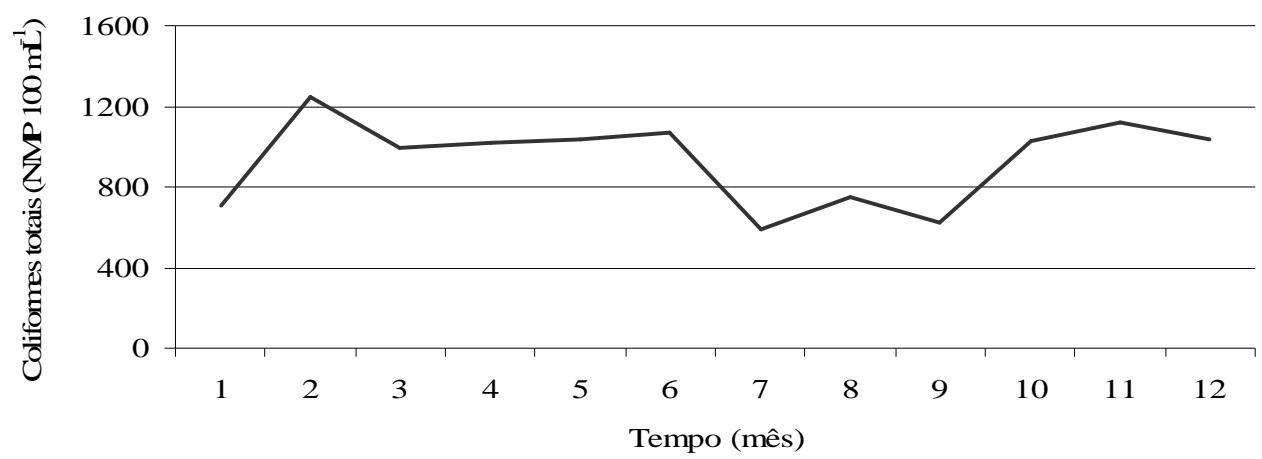

Figura 3. Médias dos resultados mensais de coliformes totais para oito poços monitorados no município de Jaboticabal - SP.

Para E. coli (Figura 4), foi constatada a presença de contaminação de forma não contínua e em períodos de chuva, no início ou no final do monitoramento. Esse fato sugere que, para a qualidade sanitária, os períodos chuvosos apresentaram maiores riscos.

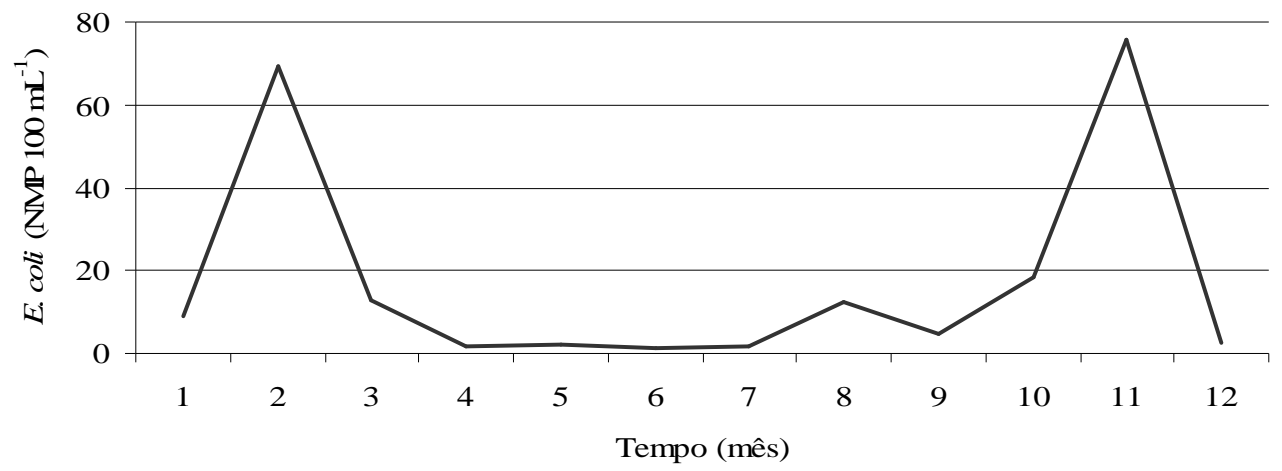

Figura 4. Médias dos resultados mensais de E. coli para oito poços monitorados no município de Jaboticabal - SP.

Amaral et al (2003) encontraram maior proporção de amostras fora dos padrões em período de chuva (90\%) do que em período de seca (83\%), para poços da área rural da região nordeste do Estado de São Paulo.

Para Aberdeenshire, Inglaterra, a variação temporal de coliformes totais e termotolerantes foi contrária a de nitrato: no segundo semestre, a porcentagem de amostras fora do padrão para nitrato diminuiu e para coliformes totais e termotolerantes duplicou (REID et al., 2003). Houve correlação positiva entre precipitação e coliformes totais, e para nitrato, nenhuma relação foi verificada. Neste estudo, poucas amostras apresentaram nitrato e coliformes fora dos padrões simultaneamente, indicando que a origem dos contaminantes foi diferente (REID et al., 2003). 
Para o pH (Figura 5), houve aumento e redução dos valores até o mês 8, seguidos de novo aumento e redução até o mês 11 (outubro/2009).

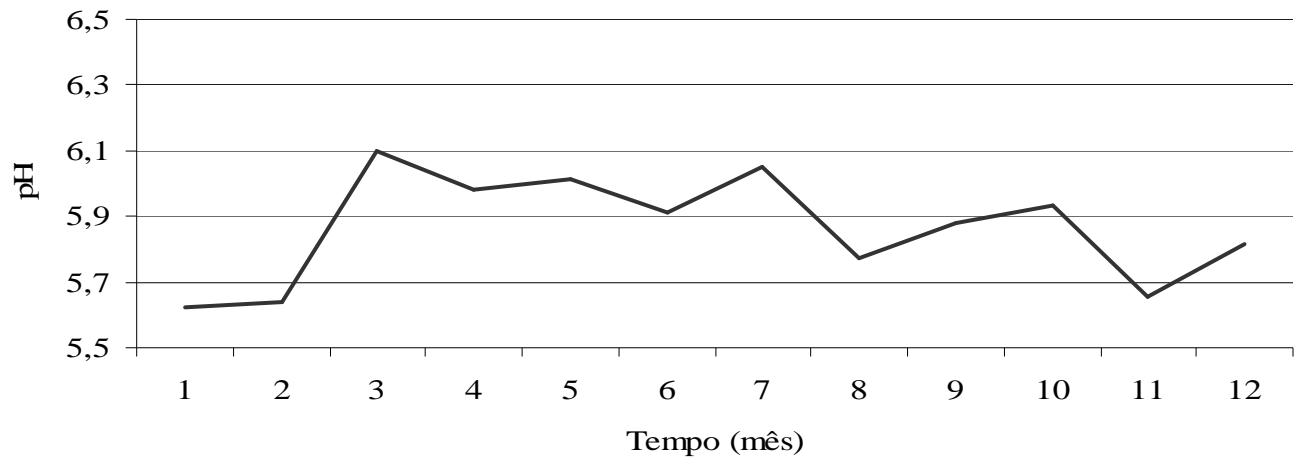

Figura 5. Resultados das médias mensais de $\mathrm{pH}$ obtidos para oito poços localizados no município de Jaboticabal - SP.

As variações de turbidez não apresentaram características sazonais acentuadas (Figura 6). Houve picos isolados nos meses 2; 4;6 e 10. Exceto para o mês 6, todos os demais se referem a período chuvoso. $\mathrm{O}$ pH de sistemas aquáticos é um importante indicador de qualidade de água e da extensão da poluição e corpos hídricos não poluídos apresentam valores próximos da neutralidade (CORADI et al., 2009).

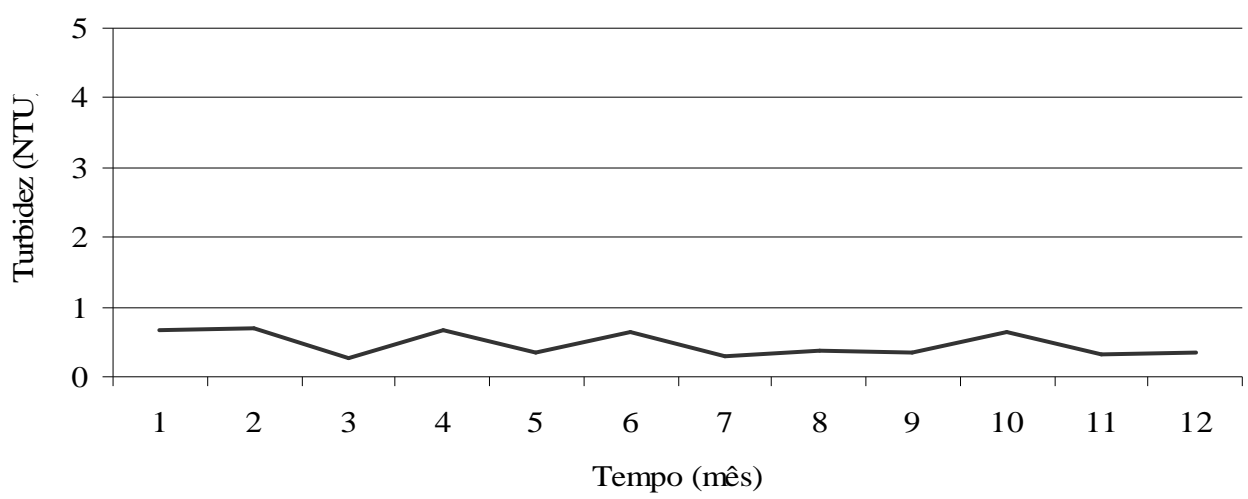

Figura 6. Resultados das médias mensais de turbidez para oito poços monitorados no município de Jaboticabal - SP.

Os resultados obtidos para cor aparente (Figura 7) apresentaram o mesmo perfil indicado pela turbidez, ou seja, sem variações sazonais acentuadas. Houve picos isolados nos meses $2 ; 6 ; 8$ e 10, sendo os meses 6 e 8 referentes ao período de seca. 


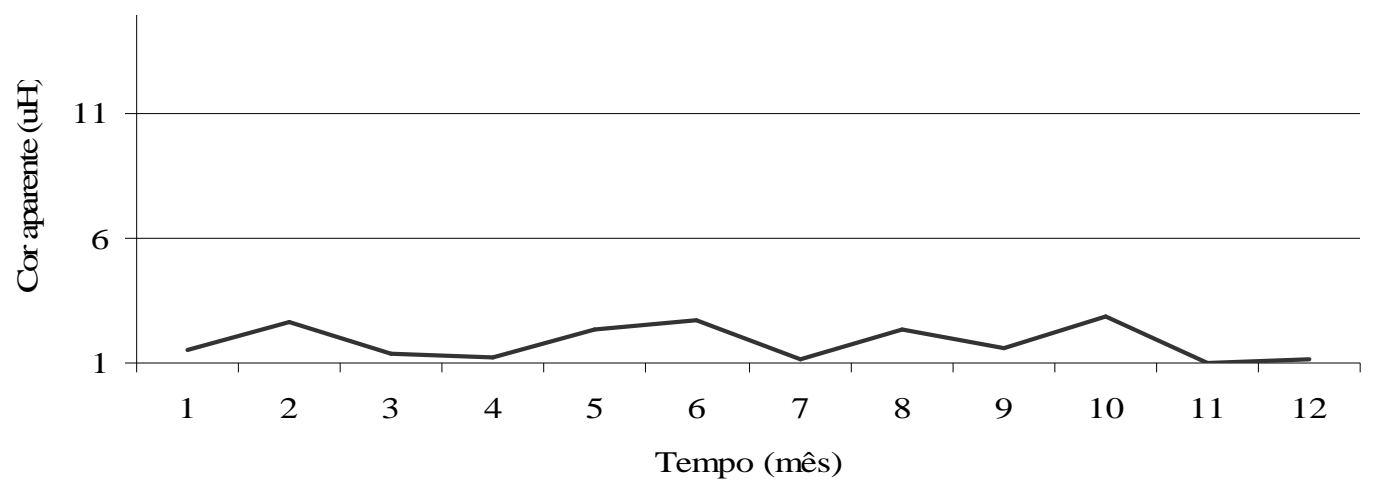

Figura 7. Médias dos resultados mensais de cor aparente para oito poços monitorados no município de Jaboticabal - SP.

\section{CONCLUSÃO}

A qualidade das águas em Jaboticabal - SP apresentou-se superior, comparadas a resultados descritos na literatura para amostras de águas de poços de outras regiões metropolitanas brasileiras. No entanto, no estudo da variação temporal, nitrato e E. coli apresentaram variações sazonais importantes, indicando que, em período chuvoso, há risco para o consumo humano.

\section{AGRADECIMENTO}

À FAPESP pelo apoio financeiro.

\section{REFERÊNCIAS}

AELION, C. M.; CONTE, B. C. Susceptibility of residential wells to VOCs and nitrate contamination. Environmental Science and Technology, Easton, v.38, p.1.648-1.656, 2004.

AMARAL, L.A. Controle da qualidade microbiológica da água utilizada em avicultura. In: MACARI, M. Água na avicultura industrial. Jaboticabal: Funep, 1996. p.93-118.

AMARAL, L. A.et al. Água de consumo humano como fator de risco à saúde em propriedades rurais. Revista de Saúde Pública, São Paulo, v.37, n.4, p.510-514, 2003.

AMARAL, L. A.et al. Avaliação da qualidade higiênico-sanitária da água de poços rasos localizados em uma área urbana: utilização de colifagos em comparação com indicadores bacterianos de poluição fecal. Revista de Saúde Pública, São Paulo, v.28, n.5, p.345-348, 1994. 
AMERICAN PUBLIC HEALTH ASSOCIATION. Standard methods for the examination of water and wastewater.16. ed. New York: APHA, 1992.

ARBUCKLE, T. E., SHERMAN, G. J.; COREY, P. N. Water nitrates and CNS birth defects: a population based case control study. Archives of Environmental Health, Washington, v.43, p.162-167, 1988.

ANTONAKOS , A.; LAMBRAKIS, N. Hidrodynamic characteristics and nitrate propagation in Sparta aquifer. Water Research, New York, v.34, p.3.977-3.986, 2000.

BARRET, M.et al. Marker species for identifying urban groundwater recharge sources: a review and case study in Nottingham, UK. Water Research, New York, v.33, n.14, p.3.083-3.097, 1999.

BEATO, D. A. C. et al. Impactos urbanos em águas subterrâneas - bacia da Lagoa da Pampulha, Belo Horizonte- MG. Revista Águas Subterrâneas, São Paulo, v.17, p.4968, 2003.

BRASIL. Ministério da Saúde. Portaria 518, de 25 de março de 2004.

CABRAL, N. M. T. Teores de nitrato $\left(\mathrm{NO}_{3}{ }^{-}\right)$e amônio $\left(\mathrm{NH}_{4}{ }^{+}\right)$nas águas do aquífero Barreiras nos bairros do Reduto, Nazaré e Umarizal - Belém - PA. Química Nova, São Paulo, v.30, n.8, p.1.804-1.808, 2007.

CETESB. Relatório de qualidade das águas interiores do Estado de São Paulo 2002. CETESB: São Paulo, 2003. 273 p.

CLAY, D. E.et al. R. Temporal variability of organic $\mathrm{C}$ and nitrate in a shallow aquifer. Water Research, New York, v.30, p.559-568, 1996.

CORADI, P. C.; FIA, R.; PEREIRA-RAMIREZ, O. Avaliação da qualidade da água superficial dos cursos de água do município de Pelotas-RS, Brasil. Revista Ambiente \& Água: An Interdisciplinary Journal of Applied Science, Taubaté, v.4, p.46-56, 2009.

FLATEN, T. P.; BOLVIKEN, B. Geographical associations between drinking water chemistry and the mortality and morbidity of cancer and some diseases in Norway. The Science of the Total Environment, Amsterdam, v.102, p.75-100, 1991.

HACH COMPANY MANUAL. Dr/2000. Spectrophotometer instrument manual for use software version 3. Loveland, 1996. 58 p.

HACH. Portable turbidimeter model 2100P instrument and procedure manual. 9. ed. Hach Company: China, 2008. 78 p.

HELENA, B. et al. Temporal evolution of groundwater composition in an alluvial aquifer (Pisuerga River, Spain) by principal component analysis. Water Research, New York, v.34, p.807-816, 2000.

HOWARDA, G. et al. Risk factors contributing to microbiological contamination of shallow groundwater in Kampala, Uganda. Water Research, New York, v.37, p.3.421$3.429,2003$ 
JÚNIOR, P. R. S.; MELLO, A. M. M. F.; CARVALHO, E. Qualidade microbiológica da água de poços residenciais do bairro centro educacional da cidade de Fátima do Sul MS. Interbio, Dourados, v.2, n.2, p.29-34, 2008.

LIU, A.; MING, J.; ANKUMAH, R. O Nitrate contamination in private wells in rural Alabama, United States. Science of the Total Environment, Amsterdam, v.346, p.112$120,2005$.

LIU, C.-Q. et al. Using $\delta^{15} \mathrm{~N}$ - and $\delta^{18} \mathrm{O}-$ Values to identify nitrate sources in karst ground water, Guiyang, Southwest China. Environmental Science and Technology, Easton, v.40, p.6.928-6.933, 2006.

LUCENA, L. R. F.; ROSA FILHO, E. F.; BITTENCOURT, A. V. L. Características hidroquímicas do aquífero Barreiras no âmbito do setor oriental da Bacia do Rio Pirangi - RN. Revista Águas Subterrâneas, São Paulo, v.18, p.29-38, 2004.

REID, D. C. et al. The quality of drinking water from private water supplies in Aberdeenshire, UK. Water Research, New York, v.37, p.245-254, 2003.

RIVETT, M. O. et al. D. Nitrate attenuation in groundwater: A review of biogeochemical controlling processes. Water Research, New York, v.42, p.4.2154.232, 2008.

SQUILLACE, P. J.; SCOTT, J. C.; MORAN, M. J.; NOLAN, B. T.; KOLPIN, D. W. VOCs, pesticides, nitrate, and their mixtures in groundwater used for drinking water in the United States. Environmental Science and Technology, Easton, v.36, p.1.9231.930, 2002.

VARNIER, C.; HIRATA, R. Contaminação da água subterrânea por nitrato no Parque Ecológico do Tietê - São Paulo, Brasil. Revista Águas Subterrâneas, São Paulo, v.16, p.97-104, 2002.

VINTEN, A. J.; DUNN, S. M. Assessing the effects of land use on temporal change in well water quality in a designated nitrate vulnerable zone. Science of the Total Environment, Amsterdam, v.265, n.1/3, p.253-268, 2001.

WAKIDA, F. T.; LERNER, D. N. Non-agricultural sources of groundwater nitrate: a review and case study. Water Research, New York, v.39, p.3-16, 2005.

WEYER, P. J. et al. Municipal drinking water nitrate level and cancer risk in older women: the Iowa women's health study. Epidemiology, Baltimore, v.12, n.3, p.327338, 2001. 